IOSR Journal of Engineering

e-ISSN: 2250-3021, p-ISSN: 2278-8719,

Vol. 2, Issue 12 (Dec. 2012) ||V2|| PP 41-43

\title{
On Timing for Addition a Control Input into a Certain Discrete System
}

\author{
Keiko Uohashi \\ Department of Mechanical Engineering \& Intelligent Systems, Faculty of Engineering, Tohoku Gakuin \\ University, Tagajo, Miyagi 985-8537, Japan
}

\begin{abstract}
In our other paper we study a certain control method for a discrete system described with power functions, which varies explosively after vibration with low amplitude during several steps or during several decades of step. In this paper we research relation with transient states and timing when adding control inputs into these systems.
\end{abstract}

Keywords :-discrete system, discrete control, difference equation, power function, controlling chaos

\section{INTRODUCTION}

In this paper we treat the following discrete system (1) with power functions;

$$
\begin{array}{ll}
\mathrm{x}_{1}(\mathrm{k}+1)=\mathrm{a}-\mathrm{x}_{1}(\mathrm{k})^{6}+\mathrm{x}_{2}(\mathrm{k})^{a}+\mathrm{u}(\mathrm{k}), & \mathrm{a}>0 \\
\mathrm{x}_{2}(\mathrm{k}+1)=\mathrm{x}_{1}(\mathrm{k})^{\mathrm{a}}, & \mathrm{k}=1,2, \ldots \\
\mathrm{x}_{1}(0)=\mathrm{x}_{2}(0)=0 . &
\end{array}
$$

In our other paper we see that $\mathrm{x}_{1}(\mathrm{k})$ and $\mathrm{x}_{2}(\mathrm{k})$ of the system (1) vibrate during several steps, and that their absolute values tend to infinity as $\mathrm{k}$ tending to infinity after vibration, for $\mathrm{a}>=0.70386$ and $\mathrm{u}(\mathrm{k})=0$ for all $\mathrm{k}$ on a discrete system [1]. We also proposed a control method for the system (1) by technique for controlling chaos [2] [3], and show stabilization of the system (1) added control inputs by numerical experiments.

In numerical experiments on [1], we add control inputs firstly at $\mathrm{k}=3$ and are adding for $\mathrm{k}>=3$. In this paper we show results of experiments for the system added firstly at each value of $\mathrm{k}$.

Our control method is referred to controlling chaos. So we hope that our method is made use of control for phenomena whose states are suddenly changed.

\section{STABILIZING INPUTS}

In this section we explain the control input proposed in [1] simply.

Let the input $\mathrm{u}(\mathrm{k})=0$ for all $\mathrm{k}$ and $\mathrm{a}=0.8$ on the system (1). Then the fixed point of the system is $\left(\alpha_{1}, \alpha_{2}\right)=(0.715,0.366)$. We set

$$
A=\left(\begin{array}{cc}
-2 \alpha_{1}{ }^{a} & 1 \\
1 & 0
\end{array}\right)
$$

We set by $\lambda_{\max }$ and $\lambda_{\min }$ the maximal eigen value of $\mathrm{A}$ and the minimal eigen value of $\mathrm{A}$, respectively. Then we have the next property of the system (1).

Fact 1. A control input

$$
\begin{aligned}
& \mathrm{u}(\mathrm{k})=\mathrm{K}\left\{\left(\begin{array}{cc}
\mathrm{x}_{1}(\mathrm{k})^{\mathrm{a}} & 0 \\
0 & \mathrm{x}_{2}(\mathrm{k})^{\mathrm{a}}
\end{array}\right)-\left(\begin{array}{cc}
\alpha_{1}{ }^{\mathrm{a}} & 0 \\
0 & \alpha_{2}{ }^{\mathrm{a}}
\end{array}\right)\right\}\left(\begin{array}{l}
1 \\
1
\end{array}\right) \\
& =1.4305\left(\mathrm{x}_{1}(\mathrm{k})^{\mathrm{a}}-0.715^{\wedge} 3\right)-\left(\mathrm{x}_{2}(\mathrm{k})^{\mathrm{a}}-0.3658^{\wedge} 3\right) \text {, } \\
& \text { where } \mathrm{K}=-\lambda_{\min }\left[\begin{array}{ll}
1 & -\lambda_{\max }
\end{array}\right]=\left[\alpha_{1}{ }^{3}+\left(\alpha_{1}{ }^{6}+1\right)^{\wedge}(1 / 2) \quad-1\right]=\left[\begin{array}{lll}
1.4305 & -1
\end{array}\right] \\
& \text { for } A=\left(\begin{array}{cc}
-2 \alpha_{1}^{a} & 1 \\
1 & 0
\end{array}\right) \text {, }
\end{aligned}
$$

stabilizes the system (1)

For $\mathrm{a}=0.705$, we obtain a similar fact, setting $\left(\alpha_{1}, \alpha_{2}\right)=(0.650,0.275)$. 


\section{NUMERICAL EXPERIMENTS}

We give numerical experiments by Microsoft Excel 2007. On each figure the abscissa means values of $\mathrm{k}$ and the ordinate means values of $\mathrm{x}_{1}(\mathrm{k})$.

We see non controlled system (1), i.e., $\mathrm{u}(\mathrm{k})=0$ for all $\mathrm{k}$, as $\mathrm{a}=0.705$ and as $\mathrm{a}=0.8$ on Fig. 1 and on the Fig. 2, respectively.

Fig. 3 shows the system (1) added a control input (3) firstly at $\mathrm{k}=1$ (solid line), firstly at $\mathrm{k}=30$ (broken line) and firstly at $\mathrm{k}=55$ (dotted line), respectively, for a $=0.705$. We are also adding a control input during $\mathrm{k}>=1, \mathrm{k}>=30, \mathrm{k}>=55$, respectively. For any first input time $\mathrm{k}$ on Fig. 3, a state variable $\mathrm{x}_{1}(\mathrm{k})$ converges to the same value. We also see that an interval from overshoot (or undershoot) to steady state is shortest for the largest first input time $\mathrm{k}$.

Fig. 4 shows the system (1) added a control input (3) firstly at $\mathrm{k}=3$ (solid line), firstly at $\mathrm{k}=4$ (broken line) and firstly at $\mathrm{k}=5$ (dotted line), respectively, for $\mathrm{a}=0.8$. We are also adding a control input during $\mathrm{k}>=3$, $\mathrm{k}>=4, \mathrm{k}>=5$, respectively. For a small first input time $\mathrm{k}$, a state variable $\mathrm{x}_{1}(\mathrm{k})$ converges to a value different from the limit for larger first input times $\mathrm{k}$. We see that an interval from overshoot (or undershoot) to steady state is shortest for the largest first input time k, similarly to the case for a $=0.705$ on Fig. 3 .

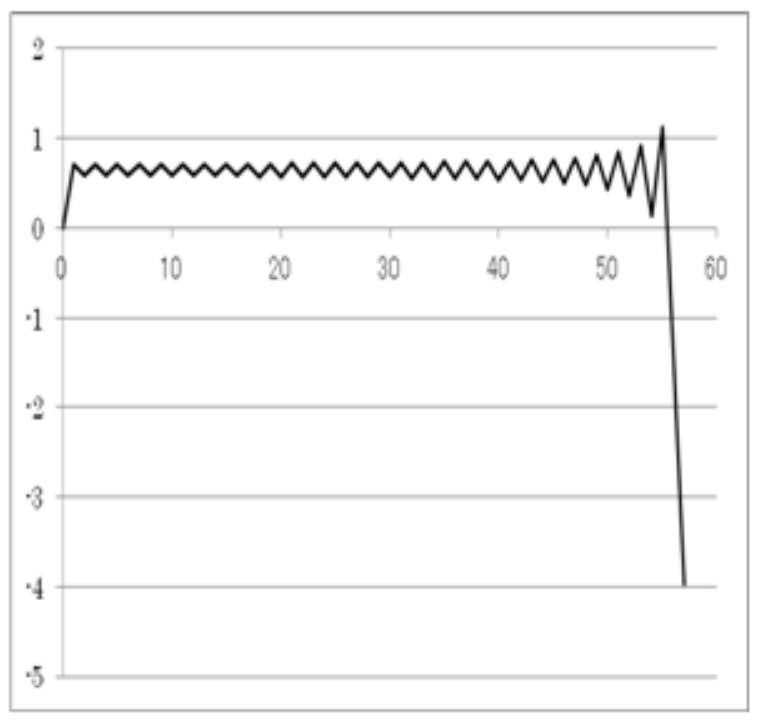

Figure 1: The system $(1)(\mathrm{a}=0.705)$

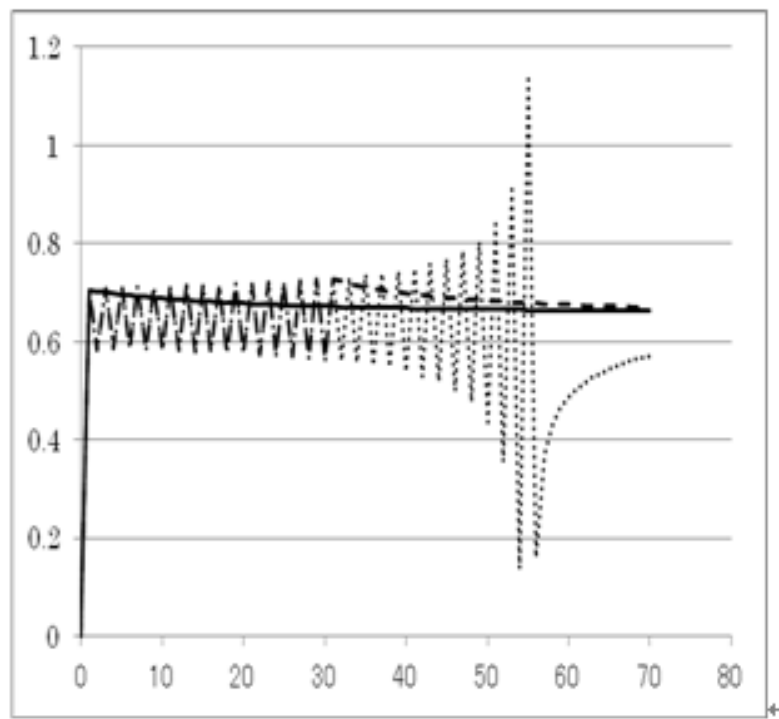

Figure 3: The stabilized system; $\mathrm{k}<=55(\mathrm{a}=0.705)$

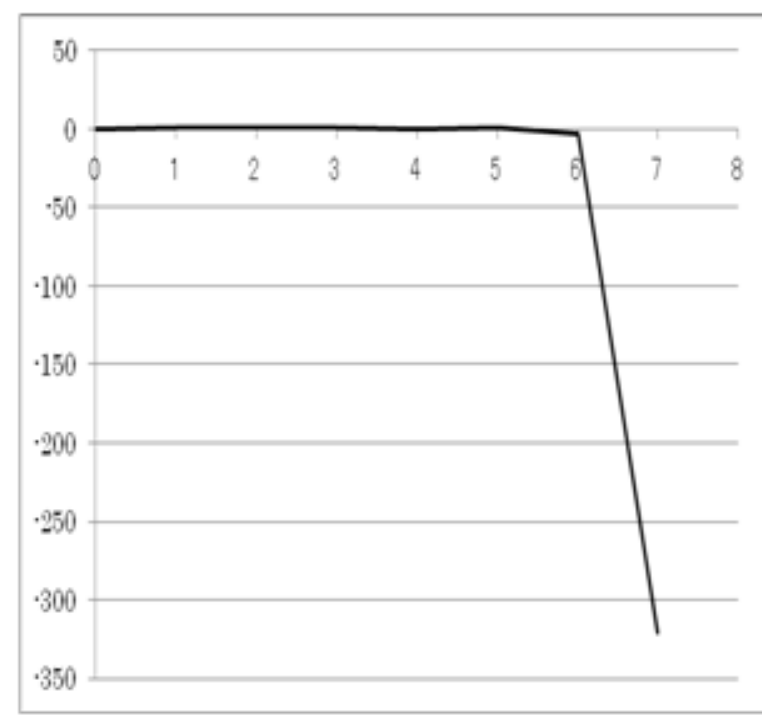

Figure 2: The system $(1)(\mathrm{a}=0.8)$

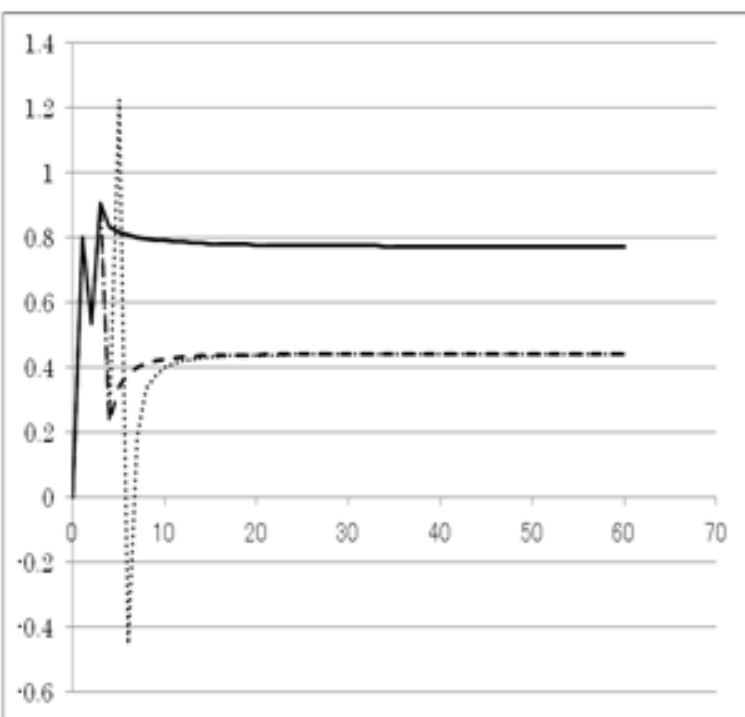

Figure 4: The stabilized system; $\mathrm{k}<=5(\mathrm{a}=0.8)$ 


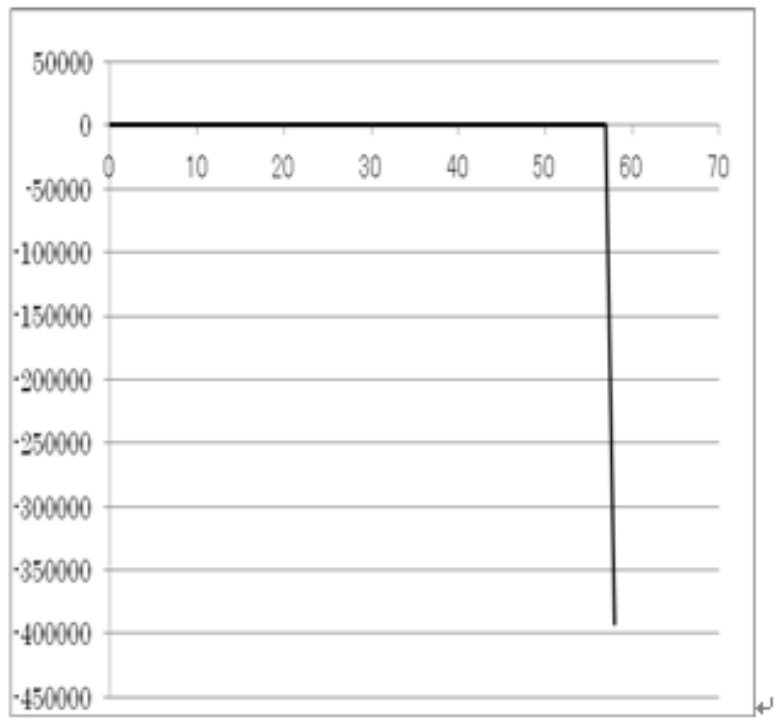

Figure 5: For a later input at $\mathrm{k}=56(\mathrm{a}=0.705)$

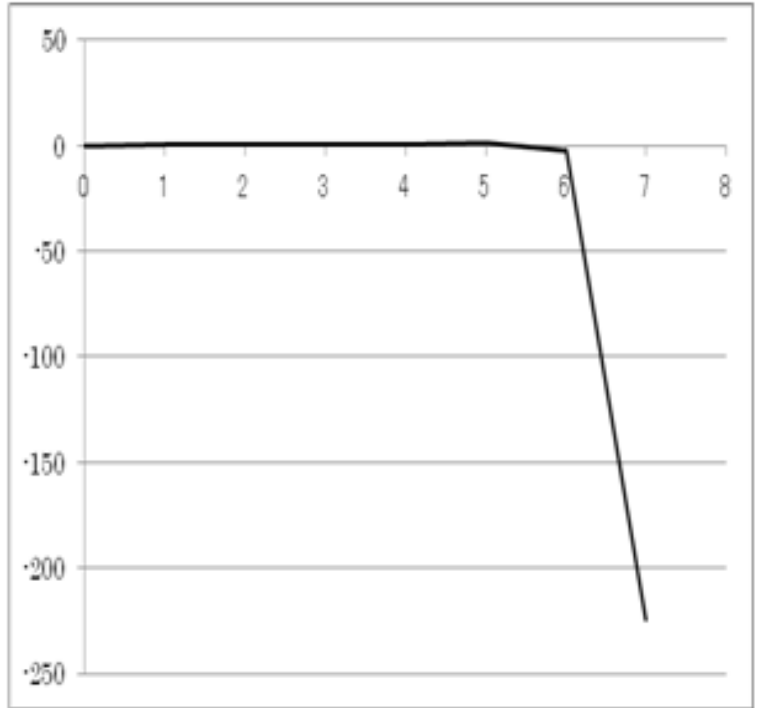

Figure 6: For a later input at $\mathrm{k}=6(\mathrm{a}=0.8)$

Fig. 5 and Fig. 6 show the system (1) added a control input (3) firstly at $\mathrm{k}=56$ for a $=0.705$, and firstly at $\mathrm{k}=6$ for $\mathrm{a}=0.8$, respectively. We are also adding a control input during $\mathrm{k}>=56, \mathrm{k}>=6$ for $\mathrm{a}=0.705, \mathrm{a}=0.8$, respectively. Comparing with Fig. 3, 4 and Fig. 5, 6, we know that only 1-difference of control started time causes huge difference of conversion or divergence.

\section{CONCLUSION}

We researched relation with transient states and timing when adding control inputs into a system with power functions. We know that relation with overshoot (or undershoot) and steady state in our system is similar to relation with them in linear systems theory. Existence of a control input stabilizing large amplitudes will be used for control of complex systems, and so on.

\section{REFERENCES}

1) K. Uohashi, A control method for a discrete system with power functions, IOSR Journal of Engineering, 2 (12), 2012, 41-43.

2) E. Ott, C. Grebogi and J.A. Yorke, Controlling Chaos, Physical Review Letters, 64(11), 1990, 11961199.

3) T. Ushio, Controlling Chaos (Asakura Shoten, 1996), in Japanese. 